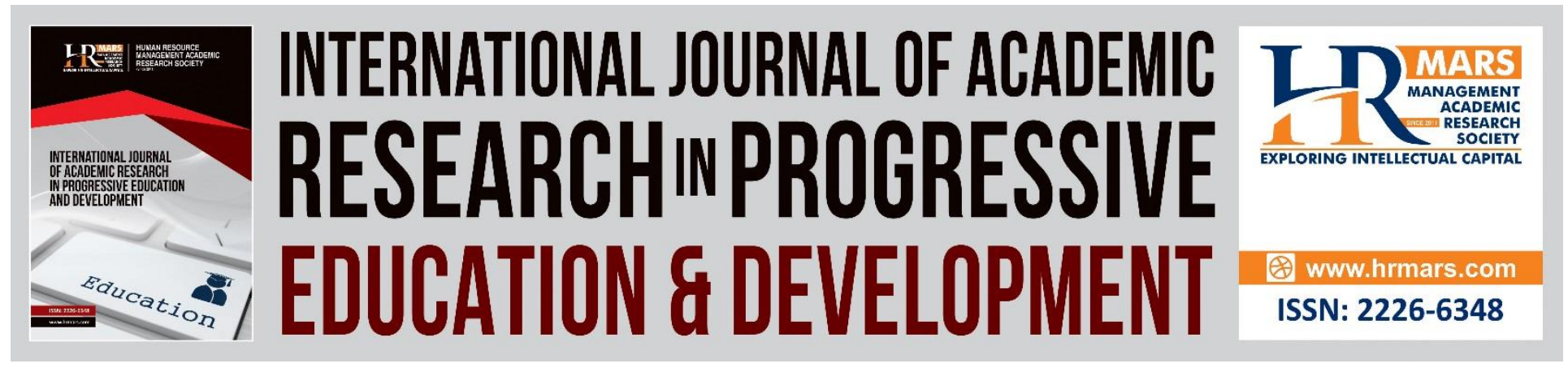

\title{
An Analysis of Relationship between Relevance at the Lexical and the Phrasal levels of Financial Budget Discourse Texts
}

Ong'ayo Francis, Dr. Ongarora David, Dr. Yakub Adams

To Link this Article: http://dx.doi.org/10.6007/IJARPED/v7-i1/3916

DOI: $10.6007 /$ IJARPED/v7-i1/3916

Received: 03 Dec 2017, Revised: 28 Jan 2018, Accepted: 30 Jan 2018

Published Online: 30 Jan 2018

In-Text Citation: (Francis, Ong'ayo \& Adams, 2018)

To Cite this Article: Francis, Ong'ayo, O. D., \& Adams, Y. (2018). An Analysis of Relationship between Relevance at the Lexical and the Phrasal levels of Financial Budget Discourse Texts. International Journal of Academic Research in Progressive Education and Development, 7(1), 111-120.

Copyright: (C) 2018 The Author(s)

Published by Human Resource Management Academic Research Society (www.hrmars.com)

This article is published under the Creative Commons Attribution (CC BY 4.0) license. Anyone may reproduce, distribute, translate and create derivative works of this article (for both commercial and non-commercial purposes), subject to full attribution to the original publication and authors. The full terms of this license may be seen at: http://creativecommons.org/licences/by/4.0/legalcode

Vol. 7, No. 1, January 2018, Pg. 111 - 120

http://hrmars.com/index.php/pages/detail/IJARPED

JOURNAL HOMEPAGE

Full Terms \& Conditions of access and use can be found at http://hrmars.com/index.php/pages/detail/publication-ethics 


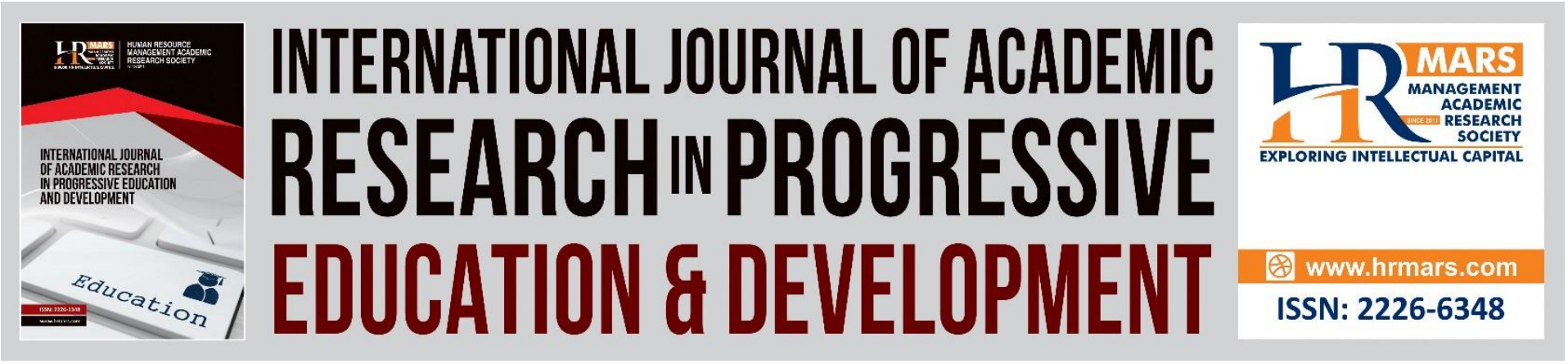

\title{
An Analysis of Relationship between Relevance at the Lexical and the Phrasal levels of Financial Budget Discourse Texts
}

\author{
Ong'ayo Francis, Dr. Ongarora David, Dr. Yakub Adams
} Department of Linguistics, School of Arts and Social Sciences, Maseno University P.O Box Private Bag, Maseno-Kenya.Email: fonyango78@yahoo.com

\begin{abstract}
In Kenya there are obstacles to access to information at the county level which include among other issues-Language barrier. This has impeded public participation hindering county development. This is augmented by Kenya Institute of Economic Affairs report, World Bank report and First Devolution Conference report. The financial jargon used in Homa Bay County's budget discourse texts hinders public participation which has formed a communication breakdown between the county government of Homa Bay and the public. Findings on Discourse Analysis from various linguists do not explain "discourse exclusion", a peculiar case where the county government and the people are constitutionally mandated to engage in a discourse but fails to do so due to relevance. This research article looked into relationship between relevance at both lexical and phrasal levels of the financial budget discourse texts of Homa Bay County Government in Kenya. A conceptual framework used was multi way interactive model (Ryan et al 1982) whose tenet is interaction of various variables. Two theories used include; Communication Accommodation Theory (Coupland \& Giles,1988) whose tenets include; source, message, transmitter and signal, received signal, receiver, and destination and Relevance Theory (Sperber \&Wilson,2004)whose tenets include; cognitive effects, processing effort and contextual assumptions. The study used descriptive design; the research area is Homa Bay County. The population includes 428,911 persons who had attained the voting age of 18 years and budget discourse texts between 2014 and 2016.Purposive sampling was used to select 43 members of the public, and 20 linguistic items that form the budget discourse text between 2014 and 2016. Data collection techniques involved; use of questionnaires, structured oral interviews, tape recording, focused group discussion and content analysis of available documents. Data analysis was done thematically and presented in textual and tabular forms; descriptive design was used. Findings show that phrasal processing effort is cognitively more involving than lexical processing effort. The study is significant in building pragmatic and translation theories, editing and enhances public communication mechanisms for the wider economic development.
\end{abstract}




\section{Introduction}

Data analysis, presentation and discussion of the relevance of the lexical and phrasal levels of the budget discourse text are presented. This article is divided into sections. The first section presents the result analysis of phrasal items which is presented in a tabular form while section two deals with lexical items. The analysis is done in form of summaries of scores for various target scale levels which cuts across both lexical and phrasal levels for all categories of respondents. After data presentation and analysis discussion is done following the results presented. The discussion is done by doing comparative analysis of various linguistic items explaining the variations of scores for various linguistic items. References are made to various tables that are used in the discussion.

\section{Statement of the Problem}

The financial jargon used in budget discourse texts hinders public participation which has formed a communication breakdown between the governments and the public; this triggers the analysis of processing effort and Homa Bay's county's budget discourse texts in Kenya. Despite its reach and popularity, however, processing effort theories are poorly understood. There is confusion among both linguists and philosophers about what relevance theorists are committed to and what kinds of explanations they attempt to give. This research analyzes the relationship between relevance at both phrasal and lexical levels of the county's budget discourse texts and determines the linguistic postulations which would show relationship between grammar and cognitive processes.

\section{Literature Review}

Relevance Theory (Sperber \& Wilson, 1986/1995) has been applied to the study of processing effort in translation, mainly by using the relevance-theoretic concepts of conceptual and procedural encodings proposed by Blakemore (2002) in order to identify a relation between processing effort and cognitive effect. In relevance-theoretic terms, the function of conceptual expressions (i.e., open lexical categories, such as nouns, adjectives and verbs) is to convey conceptual meaning which is propositionally extendable and contributes to expanding the inferential processing of an utterance, whereas the function of procedural expressions is to activate domain specific cognitive procedures (i.e., morph-syntactic constraints in utterance processing) and contributes to constraining the inferential processing of these same utterances. Relevance Theory assumes that the conceptual-procedural distinction guides inferential processing. And since most content words also carry some procedural meaning (Wilson,2011), therefore, processing effort in translation should concentrate more on instances of procedural than conceptual encodings. These findings are based on issues translation although the concepts of conceptual and procedural encodings are quite relevant to this study.

Relevance is defined as a potential property of inputs to cognitive process, whether these are external stimuli (sights, sounds, utterances, actions) or internal representations (thoughts, memories, conclusions of inferences) (Sperber \& Wilson, 2004).

Information can be relevant in one context and not in another (or more relevant in one context than another). So the basic notion is that of relevance in a context. Context means set of mentally represented assumptions used in interpreting (or processing) a given idea of information. 
Information is relevant in a context when it interacts with the context to yield what are called cognitive effects. The role of the context is central to Discourse Analysis which is the aspect under study in this research. To what extend are the county discourse texts relevant?

Cognitive effects strengthen a contextual assumption. They contradict and eliminate a contextual assumption; they combine with a contextual assumption to yield a contextual implication i.e conclusion derivable from a new information and context together. The greater the cognitive effect, the greater the relevance. This tenet is of value to my study since discourse text presents new and given information which is context based.

The fact that humans pay attention to what is relevant to them also has a consequence for communicator in the communication process; by demanding attention from audience, the communicator suggests that the information he/she is offering is relevant enough to be worth the audience's attention. Relevance is the key to communication as well. Sperber \& Wilson have therefore also formulated a communicative principle of relevance. (Sperber \& Wilson, 1995,pp. 260-261).

Understanding an utterance is affected by the processing effort required, and this has been studied within psychology. The following are factors known to affect the processing effort required for utterance comprehension: Recency of use, frequency of use, linguistic complexity and logical complexity.

Assessment of relevance depends on the cognitive affects and the processing effort needed to recover those cognitive effects and the role of the context. The cognitive principle of relevance states as follows:

Human cognition tends to be geared towards the maximization of relevance. This is the principle which (according to relevance theory given all types of information - both accidental and intentional. when someone speaks we will pay attention to any information we can pick up that seems relevant to us, whether devised from the content of the utterance their final expression and gestures, their accompanying behavior, their pauses, hesitation and so on and process this information in a context that is likely to maximize relevance.

Context is chosen by consideration of relevance. The individual chooses the context which involves the best possible balance of effort against effect. When this balance is achieved assumption are being optionally processed. (Sperber \& Wilson, 2004) an assumption is manifested to an individual at a given time if he is capable at that time of representing it mentally accepting its representation as false or as probably true. A set of assumptions that are manifested to an individual is called a cognitive environment. An individual's total cognitive environmental is a function of his physical environment and his cognitive abilities.

Grice's fundamental assumption is that communication is not only rational and purposive but also co-operative. Actually each conversation has an accepted purpose or direction in which participants work together towards the common goal of understanding and being understood this fundamental assumption is formulated as the co-operative principle (CP)It states; make your conversational contribution such as it is required, at the stage of which it occurs, by the accepted purpose or direction of engagement. (Grice, 1975).

Grice conversational maxims are: Quantity: Make your contribution as informative as required do not make your contribution more informative than required. Quality: Be relevant. Manner: Be clear and comprehensible; avoid obscuring of expressions. Avoid ambiguity. Be brief (avoid 
unnecessary prolixity).Be orderly. Relevance theory overrides Grice's maxims as it is the relevance that both the speaker and the listener opt to achieve which would dictate the use of all other maxims.

In participation in discourse we distinguish between monologue and dialogue along with medium. There are clear and central co-occurrences between medium and those of participation. The categories of medium and participation also function in a "removed" or "explanatory" way (Crystal\&Davy,1970,pp.66-71).Discourse analysis of county government texts and public participation will enable the counties to cope with exact linguistic challenges in such discourses and establish their various aspects whether "removed" or "explanatory" within the context of Homa Bay county government.

Discourse analysis can be divided into two basic categories-the text grammarians and the speech act (interactional) theorists. The text grammarians believe at least in the simplest formulations, that discourses can be viewed simply as sentences strung together in much the same way that clauses within sentences can be conjoined with connectives of various kinds. It follows that there are no problems for discourse analysis that are not problems for sentential analysis (Levinson,1983,pp.286).This augments the analysis on vagueness and ambiguities in the county government written discourse texts and to find out the extend to which they hamper public participation in the county government of Homa Bay.

The syntactic structure of utterances(or of sentences) is determined by the communicative setting of the utterance, and in particular by what is taken for granted or given as background information and what is presented against this background as being new to the hearer and thus genuinely informative (Lyons,1992,pp.227). The discourse analysis of the county government written texts and public participation will help establish how the county government communicative context displays both given and new information structure.

\section{Conceptual and Theoretical Framework}

The present study looks at the processing effort and financial budget discourse text of Homa Bay county, socio-psychological variables which are exhibited socially as people interact and communicate every day. A version of the social psychological framework by Ryan et al. (1982) that involves two variables, processing effort and the discourse text is used which exhibits a multi-way interactive paradigm.

\section{A multi-way interactive research paradigm in applied language studies}

A Processing Effort

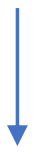

C: Communication
B Financial Budget Discourse Text

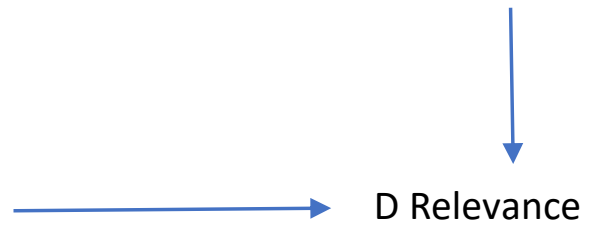

Figure 1 Source: (Ryan et al., 1982) 


\section{DEVELOPMENT}

Vol. 7, No.1, January 2018, E-ISSN: 2226-6348 @ 2018 HRMARS

The Communication Accommodation Theory (CAT) is used in this study. The tenets include source, message, transmitter, and signal, received signal, receiver, and destination. The theory also recognizes communication comprehension; a principle within Discourse Analysis. The Communication Accommodation Theory is appropriate because it is multidisciplinary. Relevance Theory is also used which is defined as a potential property of inputs to cognitive process, whether these are external stimuli (sights, sounds, utterances, actions) or internal representations (thoughts, memories, conclusions of inferences) (Sperber \& Wilson, 2004).Information can be relevant in one context and not in another (or more relevant in one context than another). So the basic notion is that of relevance in a context hence the pragmatic analysis of processing effort within the context of budget discourse texts.

\section{Research Methodology}

Descriptive research design is used because this research is not only restricted in fact findings, but is also intended to result in the formation of important principles of knowledge and solution to significant problems based on correlations and frequencies of linguistic items and levels of processing efforts (Kerlinger, 1969).Study area is Homa Bay County in the republic of Kenya. Homa Bay County lies between latitude 0o15' South and 0o52' South, and between longitudes 340 East and 350 East. The county covers an area of 4,267.1 $\mathrm{Km} 2$ inclusive of the water surface which on its own covers an area of $1,227 \mathrm{~km} 2$. The county is located in South Western Kenya along Lake Victoria. The study population involves the members of the public above eighteen years old. According to the 2009 census, Homa Bay County had 428,911 persons who had attained the voting age of 18 years, representing 41.7 per cent of the total county population (Kenya Bureau of Statistics Homa Bay County 2013). The budget discourse texts within 2014 and 2016 include: County yearly budget proposals, county budgets, County Budget Review and Outlook Paper, County Debt Management Strategy Paper, County fiscal strategy paper, Quarterly implementation report on county budget and County integrated development plan. These texts are meant for public participation and therefore accessible to the public. Purposive sampling has been used. The study involved a total of 43 members of the public with each sub county producing 7. The study looked at 20 linguistic items which were gotten from the budget discourse texts within 2014 and 2016 after the content analysis of the texts. Data Collection Techniques involved collecting information through reading secondary data and doing content analysis of available documents which included the budget documents which provided information on discourse analysis of Homa Bay county budget texts. Questionnaires were administered to the forty three members of the public.

\section{Data Analysis, Findings and Discussions \\ Result Analysis of Relevance at Phrasal Level}

Table 1 below displays the overall results of relevance of phrases of the budget discourse text. The phrases are rated as: very complex, complex, not complex and not sure. Forty three respondents were involved and each respondent filled in the questionnaire for each and every phrase rating it using the above criteria. The overall scores are as follows: Very complex had a total response score of 122, complex-103, not complex-163, not sure-39. The linguistic items investigated were ten phrases which included: Recurrent expenditure, development expenditure ,fiscal year, vote head, staff establishment, public finance, budget summary, yearly budget 
INTERNATIONAL JOURNAL OF ACADEMIC RESEARCH IN PROGRESSIVE EDUCATION AND DEVELOPMENT

Vol. 7, No.1, January 2018, E-ISSN: 2226-6348 @ 2018 HRMARS

estimates, medium term expenditure frame work and capital expenditure. The score for each phrase is displayed in the table 1 below.

Table 1: Summary of Phrases

\begin{tabular}{|l|c|c|c|c|c|}
\hline Phrases from budget Text & $\begin{array}{l}\text { Very } \\
\text { complex }\end{array}$ & Complex & $\begin{array}{l}\text { Not } \\
\text { complex }\end{array}$ & Not sure & TOTAL \\
\hline 1.RecurrentExpenditure & 8 & 9 & 23 & 3 & $\mathbf{4 3}$ \\
\hline 2.DevelopmentExpenditure & 11 & 11 & 19 & 2 & $\mathbf{4 3}$ \\
\hline 3.Fiscal Year & 11 & 13 & 16 & 3 & $\mathbf{4 3}$ \\
\hline 4.Public Finance & 11 & 9 & 20 & 3 & $\mathbf{4 3}$ \\
\hline 5.Budget Summary & 11 & 8 & 20 & 4 & $\mathbf{4 3}$ \\
\hline 6.Yearly Budget Estimates & 14 & 8 & 18 & 3 & $\mathbf{4 3}$ \\
\hline 7.Vote Head & 12 & 11 & 12 & 4 & $\mathbf{4 3}$ \\
\hline 8.Capital Expenditure & 13 & 10 & 17 & 3 & $\mathbf{4 3}$ \\
\hline $\begin{array}{l}\text { 9.Medium Term } \\
\text { Expenditure Framework }\end{array}$ & 22 & 13 & 1 & 7 & $\mathbf{4 3}$ \\
\hline 10..Staff Establishment & 9 & 11 & 17 & 6 & $\mathbf{4 3}$ \\
\hline \multicolumn{1}{|c|}{ T0TAL } & $\mathbf{1 2 2}$ & $\mathbf{1 0 3}$ & $\mathbf{1 6 3}$ & $\mathbf{3 9}$ & \\
\hline
\end{tabular}

The Table 2 below displays the overall results of relevance of lexical items of the budget discourse text. The words are rated as: very complex, complex, not complex and not sure. Forty three respondents were involved and each respondent filled in the questionnaire for each and every word rating it using the above criteria. The overall scores are as follows: Very complex had a total response score of 61 , complex-101, not complex-304, not sure-44.The linguistic items investigated were 12 words shown on Table 2.

Table 2: Summary Words /lexical levels

\begin{tabular}{|l|l|l|l|l|l|}
\hline $\begin{array}{l}\text { Lexical items } \\
\text { from budget } \\
\text { text }\end{array}$ & Very Complex & Complex & Not complex & Not sure & TOTAL \\
\hline 1.Expenditure & 2 & 11 & 28 & 2 & $\mathbf{4 3}$ \\
\hline 2Development & 5 & 9 & 27 & 2 & $\mathbf{4 3}$ \\
\hline 3. Fiscal & 9 & 9 & 14 & 11 & $\mathbf{4 3}$ \\
\hline 4 Finance & 3 & 7 & 30 & 3 & $\mathbf{4 3}$ \\
\hline 5. Budget & 4 & 5 & 31 & 3 & $\mathbf{4 3}$ \\
\hline 6. Estimates & 2 & 8 & 24 & 3 & $\mathbf{4 3}$ \\
\hline 7.Vote & 2 & 12 & 24 & 5 & $\mathbf{4 3}$ \\
\hline 8. Capital & 9 & 5 & 27 & 2 & $\mathbf{4 3}$ \\
\hline 9. Framework & 7 & 14 & 19 & 3 & $\mathbf{4 3}$ \\
\hline 10.Establishment & 8 & 7 & 26 & 2 & $\mathbf{4 3}$ \\
\hline 11. Staff & 7 & 6 & 28 & 2 & $\mathbf{4 3}$ \\
\hline 12. Summary & 3 & 8 & 26 & 6 & \\
\hline TOTAL & $\mathbf{6 1}$ & $\mathbf{1 0 1}$ & $\mathbf{3 0 4}$ & $\mathbf{4 4}$ & \\
\hline
\end{tabular}




\section{Discussion on Relevance at both Phrasal and lexical Levels}

This research relates relevance to the processing effort. Relevance is defined as a potential property of inputs to cognitive process, whether these are external stimuli (sights, sounds, utterances, actions) or internal representations (thoughts, memories, conclusions of inferences) (Sperber \& Wilson, 2004).

Information can be relevant in one context and not in another (or more relevant in one context than another). So the basic notion is that of relevance in a context. Context means set of mentally represented assumptions used in interpreting (or processing) a given idea of information. Information is relevant in a context when it interacts with the context to yield what are called cognitive effects. According to relevance theoretic framework, the higher the processing effort the lower the relevance and the lower the processing effort the higher the relevance.

Table 1 shows that the processing effort of the phrases stand at 264(very complex, complex and not sure) against 162(very complex, complex and not sure) on Table 2 of the lexical items. This data shows generally that processing phrases poses higher processing effort than the processing effort of the lexical items. This means that within the context of budget discourse text in this research, the phrasal linguistic items are less relevant than the lexical linguistic items .These results are used to explain phrasal processing effort - the relative ease or difficulty involved in processing phrases, both in and out of context. The central aim of the data in Table 1 and 2 is to contribute towards an understanding of relevance, but from a previously unexplored perspective - the 'computational level' of explanation (Marr, 1982).

In forming a computational-level explanation we can characterize relevance as cognitively depending on the processor standing at 264 against 162 of the data presented. The phrases are generally longer than words and this plays a role in increasing the processing effort hence minimizing relevance and vice versa for the words. This is in line with Genzel and Charniak's (2002) entropy rate principle which found a significant correlations between both entropy and sentence length. Their findings postulated that there is a significant positive correlation between entropy and length of a sentence. Which stipulates that the entropy rate increases with the length of the sentence predicting a higher processing effort . However, this research does not deal with the sentence length but rather the phrase and the word and goes ahead to establish relevance based on the processing effort.

\section{Findings}

On matters relevance, higher the processing effort the lower the relevance and the lower the processing effort the higher the relevance. Data shows generally that processing phrases poses higher processing effort than the processing effort of the lexical items. This means that within the context of budget discourse text in this research, the phrasal linguistic items are less relevant than the lexical linguistic items and vice versa. These results are used to explain phrasal processing effort - the relative ease or difficulty involved in processing phrases, both in and out of context.

\section{Conclusion}

Findings of this research show that relevance of phrasal items is lower than lexical items for Homa Bay County budget discourse texts. Within the phrasal linguistic categories; the processing effort 
Vol. 7, No.1, January 2018, E-ISSN: 2226-6348 @ 2018 HRMARS

would differ according to phrasal length. The phrasal category can also attract a higher processing effort depending on its own linguistic complexity but not necessarily the length only. These findings are in line with (Forster \& Chambers, 1973) who state that different stimuli will in general require different amounts of processing effort. For example, longer sentences will (other things being equal) require more effort to process than a shorter one. However, this research presents a point of divergence because it deals with specifically phrase and words not just sentence length.

\section{References}

Ager, D. (1990). Sociolinguistics and contemporary French. New York: Cambridge University Press.

of African Studies, 4 (2),50-72.

Anderson, E. A. (1974). Language beliefs, attitudes, and values: A Study in linguistic cognitive frameworks. PhD Thesis: Georgetown University.

Ashcroft, B., Griffiths, G., \& Tiffin, H. (1989). The empire writes back. London: Routledge.

Atieno-Odhiambo, E. S. ( 2003). The cultural dimensions of development in Africa. Egerton Journal,4(2) \&(3),13-31.

Cargile, A. C., Giles H., Ryan E.B., \& Bradac, J.J.(1994). Language attitudes as a social process:Aconceptual model and new directions. In Language and Communication,14(3),211-236.

Chambers, J.K. (1995). Sociolinguistic theory: Linguistic variation and its social significance.Oxford:Blackwell.

Coopers, R. L. (1989). Language planning and social change. Cambridge:Cambridge University Press.

Coupland, N., \& Giles,H. (1988). Introduction: The communicative contexts of accommodation In Language and Communication,8,175-182.

Coates, J. (1986). Women, men and language: A Sociolinguistic Account of Gender Differences in Language. London: Longman.

Coyne, C. (2007). Culture, common knowledge and post-conflict development .In Journal of Intercultural Communication. Issue 13, March 2007.

Crystal, D., \& Davy, D.(1970). Investigating English style. London: Longman Grp Ltd.

Giles, H., \& Coupland, N. (1991). Language: Contexts and consequences. Keynes: Open University Press.

Giles, H., \& Powesl, P. F. (1975). Speech style and social evaluation. London: Academic Press.

Kerlinger,F.N.(1973).Foundation of behavioral research. New York: Holt, Renehart \& Winston.

Kombo,D.K.,Tromp,D.L.A (2006). Proposal and thesis writing: An Introduction. Nairobi: Paulin Publications Africa.

Lambert, W. (1972). A Social psychology of bilingualism In teaching English as a second language: A book of readings. Toronto:McGraw-Hill.

Lakoff, R. (2004) Language and woman's place: text and commentaries. New York: Oxford University Press

Laponce, J. (1987). Languages and their territories. Toronto: University of 
INTERNATIONAL JOURNAL OF ACADEMIC RESEARCH IN PROGRESSIVE EDUCATION AND DEVELOPMENT

Vol. 7, No.1, January 2018, E-ISSN: 2226-6348 @ 2018 HRMARS

Toronto.

Levinson, S. C. (1983).Pragmatics. Cambridge: Cambridge University Press.

Lodhi, A. Y. (1993). The Language Situation in Africa Today. In Nordic Journal of African Studies.2(1),79-86.

Long, N. (1977). Introduction to the sociology of rural development. London: English Language Book Society.

Lyons, J.(1992).Language and linguistics. Cambridge University Press.

Maluleke, J. M. (2005). Language as an instrument of power. Unpublished, MA Thesis:University of South Africa.

Mazrui, A. (1990). Cultural forces in world politics. London: James Currey.

Mazrui, A. (1995). The political economy of an African language. Nairobi: East African Educational Publishers.

Mazrui, A.A., \& Mazrui, A.M (1998). The Power of Babel. Oxford, England: James Currey.

Mazrui, A. A., \& Mazrui, A. M. (1995). Swahili state and society. Nairobi: East African Educational Publishers.

Mbaabu, I. (1996). Language policy in East Africa: A Dependency theory perspective. Nairobi: East African Educational Publishers.

Sperber, D., \& Wilson, D. (1995).Relevance theory. Cambrige: Cambrige university press. Sperber, D., \& Wilson, D. (2004).Relevance theory. Cambrige: Cambrige university press. 